\title{
NHS chief admits to errors in costing of pay reform
}

\author{
Adrian O'Dowd London
}

The government miscalculated the full cost of the pay reforms in the NHS, its chief executive admitted to MPs this week.

Mr Nicholson was giving evidence to the House of Commons Committee of Public Accounts as part of its one-off inquiry into the National Audit Office and Audit Commission report Financial Management in the NHS, which was published in June.

"As far as the department is concerned we could be better at costing some of our policies," he said. "There are some examples of policies we have costed that in practice have for a whole variety of reasons cost more."

This included the reforms of the pay system, he added. But although financial problems in the NHS had worsened in recent years NHS finances had become increasingly transparent.

The committee's chairman, the Conservative MP Edward Leigh, highlighted the report's concerns about financial management capabilities at 30\% of NHS organisations.

Mr Nicholson admitted that some examples of poor management and financial practice could be found in the NHS. However, when asked whether or not trusts had sufficient financial management skills to cope he said: "Most organisations do balance their books and manage their financial affairs adequately, but there are some areas where we undoubtedly need improvement."

MPs asked whether he could ensure that essential NHS services would be maintained after the redundancies and ward closures caused by financial deficits. He replied, "We are satisfied that the development in health services in the NHS over the next 12 months will deliver the things we want it to deliver in terms of the major six priorities that the department has identified.

"We are satisfied that vital services are being protected and, indeed, developed if not improved."

The chief executive was also quizzed about the fact that some medical and healthcare graduates were unable to find jobs and that this situation would worsen in three years' time, as the NHS would have a surplus of staff.

"In terms of people coming out of colleges now what the NHS cannot do is guarantee a job to everybody who goes through that. We're not there to do that-we deliver health care. But we can do a lot to help and support people who are finding themselves in difficulty at the moment," he said. Examples of that help included giving people part time work or more training or retraining.

"There's no doubt that we have to take a long, hard look at the numbers and the workforce planning arrangements that we have in the NHS," he said.

\section{More than half a million Iraqis have been killed since invasion}

\author{
Owen Dyer London
}

More than half a million Iraqi people, about one in 40 of the country's population, have died from violent causes since the March 2003 invasion, a study in the Lancet says.

The figures in the paper, which was published online ahead of print publication on 12 October, are based on a cross sectional survey involving 1849 households with 12801 people in 47 clusters throughout Iraq (www.thelancet.com, doi: 10.1016/ S0140-6736(06)69 491-9).

The survey looked at the number of deaths between January 2002 and July 2006. In the sample 629 violent deaths were reported, 82 before the invasion and 547 since the invasion. The researchers found that mortality had risen sharply in every year since the invasion.

The researchers, from Johns Hopkins Bloomberg School of the invasion.
Public Health, Baltimore, and Baghdad's al Mustansiriya University, estimate that Iraq has had 654965 (95\% confidence interval 392979 to 942 636) excess deaths in the last three years as a consequence of the war. They estimate that 601027 (426369 to 793663 ) Iraqis have died violently since

Most of the victims of violence were men aged 15 to 44 years.

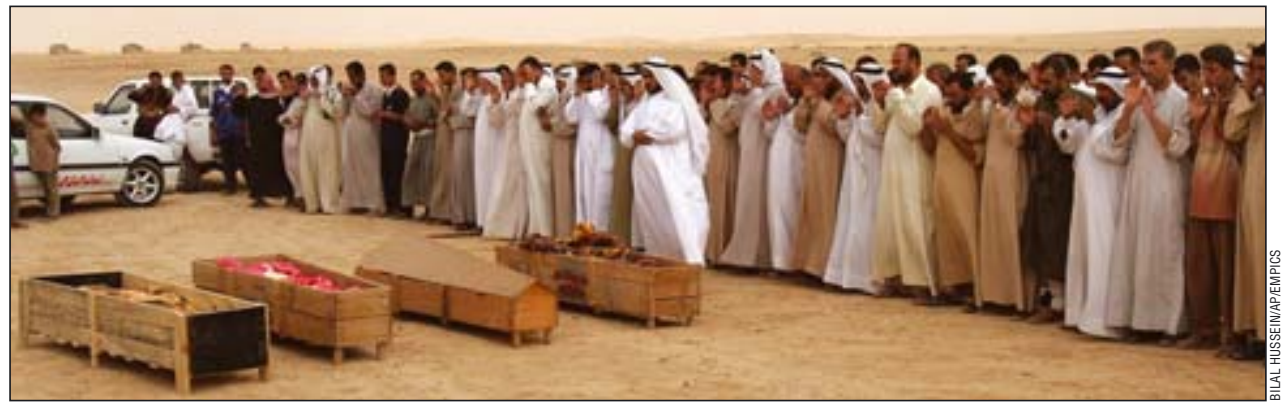

Iraqis pray next to the coffins of victims of US airstrike in Ramadi, Iraq, on Monday 17 October 2005
The most common cause of violent death was gunshot, although the number of car bomb fatalities has risen recently. The interviewers asked to see death certificates in $87 \%$ of cases, and these were produced by $90 \%$ of the respondents who were asked.

Thirty one per cent of the deaths were attributed to coalition forces. Although the proportion of deaths caused by coalition forces has fallen in the past two years, the crude number has climbed.

The violence has grown steadily over the three years, and the number of deaths has been particularly high in the past 12 months, says the study's lead author, Gilbert Burnham. The findings indicate that Iraqis may currently be being killed at a rate of about 1000 a day, he says.

The survey is the second undertaken in Iraq by the team. Like the first, its results are well in excess of estimates that are based on passive surveillance. The first study, published in November 2004 (Lancet 2004;364:1857-64), estimated that 100000 excess deaths had occurred since the March 2003 invasion, although the confidence interval was very wide.

(See Analysis and comment, p 847.) 